\title{
Feto-Placental Steroid Metabolism in Growth Retarded Human Fetuses ${ }^{1}$
}

\author{
JOHN W. REYNOLDS, BRENDA J. BARNHART, AND CHRISTINA V. CARLSON \\ Department of Pediatrics, Oregon Health Sciences University, Portland, Oregon 97201
}

\begin{abstract}
The goal of the study was the determination of the relative roles of the placenta and the fetus in causing low serum estriol $\left(E_{3}\right)$ levels in women bearing fetuses with intrauterine growth retardation (IUGR). Umbilical venous levels of $\mathrm{E}_{3}$ and dehydroepiandrosterone sulfate (DHAS) were measured in 31 samples from fetuses with IUGR, 21 of whom were vaginally delivered and 10 who were delivered by cesarean section. In addition, estrone $\left(E_{1}\right)$ and estradiol $\left(E_{2}\right)$ were measured in 11 of the samples. The results were compared with 11 samples from cesarean section delivered control term infants and $\mathbf{5 4}$ samples from vaginally delivered control infants. The vaginally delivered IUGR group had a significantly lower mean umbilical venous DHAS level than did their control group (2128 \pm $158 \mathrm{ng} / \mathrm{ml}$ SEM versus $2645 \pm 130, p<0.05$ ). Both the vaginally delivered and cesarean section delivered IUGR infants had umbilical venous $E_{3}$ levels significantly lower than in their control groups $(70 \pm 10 \mathrm{ng} / \mathrm{ml} \mathrm{SEM} \mathrm{versus}$ $144 \pm 10, p<0.001$, and $46 \pm 11 \mathrm{ng} / \mathrm{ml} \mathrm{SEM}$ versus 136 $\pm 23, p<.01$, respectively). Umbilical venous $E_{1}$ and $E_{2}$ levels were not different from the control values. $E_{1}, E_{2}$, $E_{3}$, and DHAS were measured in eight maternal venous samples obtained from mothers bearing fetuses with IUGR. In comparison with 11 control mothers, only $\mathbf{E}_{3}$ was significantly different $(10.7 \pm 3.0 \mathrm{ng} / \mathrm{ml} \mathrm{SEM} \mathrm{in}$ mothers with IUGR fetuses versus $25.0 \pm 4.9$ in control mothers $p<0.01$ ). The study provides evidence for reduced DHAS secretion in one group of the fetuses with IUGR, and no evidence for decreased placental conversion of DHAS to the estrogens $E_{1}$ and $E_{2}$. The significantly low $\mathrm{E}_{3}$ values in both umbilical and maternal samples are postulated to result not only from the reduced fetal adrenal DHAS secretion, but also underactive $16 \alpha$-hydroxylase activity in fetal liver or low efficiency of $16 \alpha-\mathrm{OH}-\mathrm{DHAS}$, relative to DHAS, as a substrate for placental conversion to an estrogen. (Pediatr Res 20: 166-168, 1986)
\end{abstract}

\section{Abbreviations}

IUGR, intrauterine growth retardation

DHAS, dehydroepiandrosterone sulfate

$\mathbf{E}_{1}$, estrone

$\mathbf{E}_{2}$, estradiol

$\mathbf{F}_{3}$, estriol

Reccived $\Lambda$ pril 8, 1985; accepted September 26, 1985.

Reprint requests John W. Revnolds. M.D. Department of Pediatrics, Oregon Health Sciences University, Portland. OR 97201.

This research was supported by a grant from the Medical Research Foundation of Oregon, and by NIH Grant HD-12027.

'Reported in part at the Western Society for Pediatric Research, Carmel, CA, 1983 (Clin Res 31:138A. 1983)
Women bearing fetuses with IUGR frequently have low serum $E_{3}$ levels in late gestation $(1,2)$. One origin of the low $E_{3}$ production in these pregnancies may be reduced secretion of fetal adrenal cortex-derived neutral steroid precursors of estriol synthesis in the placenta (3). However, there is evidence that placental conversion of the neutral precursors to estrogen may be low in association with a fetus with IUGR (4). In order to investigate the relative importance of these two possible causes of low $\mathrm{E}_{3}$ production, umbilical venous, and maternal venous neutral steroid and estrogen levels were assessed in a series of pregnancies in which the fetus had IUGR.

\section{MATERIALS AND METHODS}

Patients. All pregnant women studied in this investigation were hospitalized in the Oregon Health Sciences University Hospital. Fetuses with IUGR were diagnosed when their birth weights were more than $2 \mathrm{SD}$ below the mean for gestational age, as defined by the Babson and Benda (5) fetal growth curves. No fetuses with congenital infections or major anomalies were included in the study.

The maternal diagnoses included pregnancy-induced hypertension, chronic hypertension, chronic abruptio placenta, placenta previa, bifid uterus, and chronic leakage of amniotic fluid. A number of cases had fibrotic placentas with no obvious associated maternal pathologic process. The number of patients in each subcategory were insufficient to allow comparisons of patients in the subgroups.

Umbilical venous blood samples were obtained from 31 fetuses with IUGR, 21 of whom were delivered vaginally and 10 by cesarean section. All but two were 37 wk gestation or older. DHAS and unconjugated $\mathrm{E}_{3}$ were determined in all samples, and in 11 samples, $E_{1}$ and $E_{2} 17 \beta$ were measured in addition. Six of these 11 samples were from vaginally delivered infants and five from infants delivered by cesarean section. Maternal blood samples were collected a few hours prepartum from eight of the mothers of the latter group of 11 infants for $E_{1}, E_{2}, E_{3}$, and DHAS concentration measurements. All of these eight pregnancies were 38 wk gestation or more.

Control samples for steroids in umbilical venous serum and maternal venous serum from cesarean section deliveries were obtained from 11 women at term with uncomplicated pregnancies. Each had a weight gain of 20-35 lb, normal blood pressure, did not smoke, and took no medications chronically. Each woman was delivered via elective cesarean section prior to labor. The maternal venous samples were obtained within $12 \mathrm{~h}$ of delivery. Control values for umbilical venous steroids of fetuses from women with vaginal deliveries were obtained from 54 samples collected from women with normal pregnancies at term previously reported by Barnhart et al. (6).

Steroid assay procedures. The procedure for the DHAS-radioimmunoassay was described by Turnipseed et al. (7) except that dextran coated charcoal was used to separate bound from free 
steroid. The method for unconjugated $\mathrm{E}_{3}$ assay was described by Barnhart et al. (6), and cortisol was measured as described by Barnhart et al. (6).

Unconjugated $E_{1}$ was extracted from serum samples with benzene. An antiestrone-6-(CMO) bovine serum albumin antibody E-001 from Steranti Research Ltd. was used for the radioimmunoassay system in a 1:1000 dilution, and dextran-coated charcoal was used for bound and free steroid separation. The cross-reactivities of the $E_{1}$ antibody were $\left(E_{1}-100 \%\right): E_{2} 17 \beta-$ $0.1 \%, \mathrm{E}_{3}-0.01 \%$, DHA $-0.01 \%$, progesterone $-<0.01 \%$. Intraassay variability was $2.1 \%$ and interassay variability was $13.2 \%$

Unconjugated $E_{2}$ was assayed in serum samples extracted with benzene. A rabbit anti- $E_{2}$ antibody (R-14) provided by Dr. L. Don Keith, Veteran's Administration Hospital, Portland, OR was used at a 1:400,000 dilution, and dextran-coated charcoal was used for bound and free steroid separation. The crossreactivities of the $\mathrm{E}_{2}$ antibody were $\left(\mathrm{E}_{2}-100 \%\right): \mathrm{E}_{1}-2.0 \%, \mathrm{E}_{3}-$ $0.2 \%$, DHA $-0.01 \%$, testosterone- $0.06 \%$, cortisol- $0.03 \%$. Intraassay variability was $7.0 \%$ and interassay variability was $13.0 \%$.

The significance of differences between means was determined by use of Student's $t$ test.

\section{RESULTS}

Umbilical venous serum levels of DHAS and $E_{3}$ in 21 samples from vaginally delivered infants with IUGR and 10 from infants with IUGR delivered by cesarean section are listed in Table 1. In addition, $E_{1}$ and $E_{2}$ were assayed in six of the vaginally delivered and five of those delivered by cesarean section (Table 1). Values of $E_{1}, E_{2}, E_{3}$, and DHAS in 11 control umbilical venous samples from infants delivered by cesarean section and values of $E_{3}$ and DHAS in 54 samples from vaginally delivered control infants are included in Table 1 for comparison. The umbilical venous $E_{1}$ and $E_{2}$ values in the IUGR infants are similar to those of the control infants. The umbilical $E_{3}$ values in both subgroups of IUGR infants are significantly less than $E_{3}$ values in the control groups: IUGR (vaginal) versus control (vaginal) $-70 \pm 10 \mathrm{ng} / \mathrm{ml}(\mathrm{SEM})$ versus $144 \pm 10(p<0.001)$; IUGR (cesarean section) versus control (cesarean section)-46 $\pm 11 \mathrm{ng} / \mathrm{ml}(\mathrm{SEM})$ versus $136 \pm 23(p<0.01)$. The mean umbilical venous DHAS value in the vaginally delivered subgroup of IUGR infants is significantly less than that in the control vaginally delivered group: $2128 \pm 158 \mathrm{ng} / \mathrm{ml}$ (SEM) versus $2645 \pm 130$, respectively $(p<0.05)$.

Table 2 shows the maternal venous levels of $E_{1}, E_{2}, E_{3}$, and DHAS in mothers of eight of the 11 fetuses with IUGR listed in Table 1 who had the same serum steroids assayed. The steroid values in control prepartum samples from the 11 control women

Table 1. Steroid concentrations in umbilical venous serum samples of IUGR and control infants*

\begin{tabular}{|c|c|c|c|c|c|c|}
\hline & $n$ & $E_{1}$ & $\mathrm{E}_{2}$ & $n$ & $E_{3}$ & DHAS \\
\hline \multicolumn{7}{|l|}{ Control } \\
\hline Vaginal & & & & 54 & $144 \pm 10 \dagger$ & $2645 \pm 130 \ddagger$ \\
\hline $\begin{array}{r}\text { Cesarean } \\
\text { section }\end{array}$ & 11 & $32.1 \pm 6.4$ & $13.7 \pm 1.7$ & 11 & $136 \pm 23 \S$ & $2034 \pm 220$ \\
\hline \multicolumn{7}{|l|}{ IUGR } \\
\hline Vaginal & 6 & $31.6 \pm 6.2$ & $14.8 \pm 2.8$ & 21 & $70 \pm 10 \dagger$ & $2128 \pm 158+$ \\
\hline $\begin{array}{r}\text { Cesarean } \\
\text { section }\end{array}$ & 5 & $25.7 \pm 7.6$ & $10.6 \pm 2.1$ & 10 & $46 \pm 11 \S$ & $1508 \pm 213$ \\
\hline
\end{tabular}

Table 2. Steroid concentrations in maternal venous blood samples from pregnancies with IUGR and normal wt newborn infants*

\begin{tabular}{lrrccc}
\hline & $n$ & \multicolumn{1}{c}{$\mathrm{E}_{1}$} & $\mathrm{E}_{2}$ & $\mathrm{E}_{3}$ & DHAS \\
\hline Control & 11 & $15.2 \pm 2.6$ & $26.5 \pm 2.9$ & $25.0 \pm 4.9 \dagger$ & $594.7 \pm 119$ \\
IUGR & 8 & $8.6 \pm 1.6$ & $21.1 \pm 3.0$ & $10.7 \pm 3.0 \dagger$ & $911.7 \pm 227$ \\
\hline
\end{tabular}

$*$ Values recorded as $\mathrm{ng} / \mathrm{ml} \pm \mathrm{SEM}$.

$\dagger$ IUGR vs control $p<0.01$.

delivered by cesarean section are listed for comparison. Only the $\mathrm{E}_{3}$ level differed in the two groups. The mean value of $10.7 \pm 3$ $\mathrm{ng} / \mathrm{ml}$ is significantly lower $(p<0.01)$ in the women carrying fetuses with IUGR than the value of $25.0 \pm 4.9 \mathrm{ng} / \mathrm{ml}$ in the control women.

\section{DISCUSSION}

Adrenocortical function of growth retarded fetuses has long been known to be potentially abnormal. Naeye (8) described the adrenal cortex of the IUGR newborn infant as relatively smaller than other organs, with the fetal zone even more retarded than the permanent zone. In a study by Reynolds and Mirkin (3), newborns with IUGR were shown to have reduced urinary excretion of $16 \alpha$-hydroxy DHAS, a metabolic product of DHAS which is secreted mainly by the fetal zone of the adrenal cortex. However, these infants had normal urinary levels of the metabolic products of cortisol, $6 \beta$-hydroxy cortisol and tetrahydrocortisone, which is secreted mainly by the permanent zone. In another group of IUGR newborns 36 wk gestation or greater studied on the 1st day of life, the serum DHAS levels were found to be significantly lower than in normally grown newborn infants of the same gestational age (7).

Further evidence of disturbed adrenocortical function in the IUGR group comes from reports that the mean maternal serum $E_{3}$ levels $(1,2)$ and maternal urinary excretion of $E_{3}(9)$ are lower than expected for the duration of gestation and fetal size in women bearing a fetus with IUGR. As more than $90 \%$ of $\mathrm{E}_{3}$ in a woman in late pregnancy is derived from fetal adrenal-derived neutral steroid precursors, principally DHAS (10), diminished levels of maternal $E_{3}$ generally are considered to indicate abnormally low fetal adrenocortical steroid secretion.

In the sequence of biosynthetic steps leading from DHAS to $\mathrm{E}_{3}$, the DHAS first undergoes $16 \alpha$-hydroxylation in the fetal liver, then in the placenta undergoes conversion to $E_{3}$. The placental enzymes necessary for the biosynthesis of $E_{3}$ from $16 \alpha$ $\mathrm{OH}$-DHAS include sulfatase, $3 \beta$-hydroxysteroid dehydrogenase, and aromatizing enzymes. Potentially, a diminished activity of any one of these enzymatic steps could lead to low $E_{3}$ production in the fetoplacental unit in the face of normal adrenal DHAS secretion. Hepatic $16 \alpha$-hydroxylase has been reported to be low in association with normal fetal DHAS production, in only one instance (11). The fetus had cirrhosis, and the mother had increased $E_{1}$ and $E_{2}$ excretions, and abnormally low $E_{3}$ excretion. In normal pregnancies, the placental enzymes are considered to have a large capacity, and not to be rate limiting in estrogen biosynthesis (12). Their activities show no correlation with urinary estrogen levels over a wide range of estrogen excretions (12).

In abnormal placentas, steroid metabolizing enzymes assessed in vitro have been variously reported to be low $(4,13)$ or increased (14) in mothers with toxemia, or in mothers bearing IUGR fetuses. There are recent studies indicating that in vivo placental conversion of DHAS to $E_{1}$ and $E_{2}$ is depressed in women with fetuses showing IUGR (15-17). In addition, diminished clearance of DHAS by these patients is shown by a prolonged halflife of administered DHAS $(18,19)$. The placental clearance of DHAS by conversion to $E_{2}$ appears to be a direct reflection of 
uteroplacental blood flow (20), and the reduced clearance in women bearing fetuses with IUGR is most probably related to the high frequency of vascular pathology (21) and the reduced blood flow (22) found in the placentas of these pregnancies. Thus, in pregnancies where uteroplacental blood flow is reduced as part of a pathologic process, the placental role in estrogen production may be limiting in proportion to the decrease in placental blood perfusion, as well as limiting because of the pathologic damage to the placenta itself.

The results of the present study indicate that in the IUGR groups studied there was some, although inconsistent, evidence that fetal adrenocortical function was disturbed. There were significantly lower umbilical venous DHAS levels in the vaginally delivered IUGR infants than in the normally grown control group of vaginally delivered infants, suggesting a reduced fetal adrenocortical secretion of DHAS in the subgroup with IUGR. The mean umbilical serum DHAS level in the IUGR subgroup delivered by cesarean section was somewhat lower than in their control group of normally grown cesarean section delivered infants, but the difference did not reach the level of significance.

The reductions in umbilical venous $E_{3}$ levels in the IUGR groups, as compared to the control groups, were more consistent and were of greater magnitude than were the reductions in DHAS levels. This difference in the patterns of DHAS and $\mathrm{E}_{3}$ reductions suggested that there was not only a fetal factor, but also a placental factor in the causation of the low umbilical venous and maternal venous $\mathrm{E}_{3}$ levels. To investigate the role of a general placental aromatizing enzyme underactivity as a cause of the low umbilical venous $E_{3}$ levels, umbilical venous $E_{1}$ and $E_{2}$ levels were measured in a subset of 11 cord blood samples, and $E_{1}, E_{2}$, $E_{3}$, and DHAS were measured in maternal venous samples obtained from the mothers of eight of these 11 infants. The umbilical venous $E_{1}$ and $E_{2}$ levels were in the normal range. The maternal $E_{3}$ levels were found to be significantly low. The maternal venous $E_{1}$ and $E_{2}$ levels were lower and the DHAS levels were higher in the IUGR group, but the differences from the control group did not reach significant levels. However, the differences suggest an underactivity of placental aromatizing enzymes in mothers of IUGR fetuses.

The normal umbilical venous $E_{1}$ and $E_{2}$ levels would indicate that there was not a general reduction of the placental enzymes responsible for conversion of neutrai fetal steroids to estrogens. It is possible that the neutral steroid precursor of $\mathrm{E}_{3}, 16 \alpha-\mathrm{OH}$ DHAS, is a less efficient substrate for the placental enzymes than is DHAS, the neutral steroid precursor of $E_{1}$ and $E_{2}$. There is no in vitro evidence for this possibility, although it has been suggested by in vivo studies in women in late pregnancy (23).

Another possible explanation for the discrepancy in umbilical DHAS and $E_{3}$ levels is a reduced fetal hepatic $16 \alpha$-hydroxylase activity, as well as reduced DHAS secretion, in fetuses with IUGR. Nothing is known about the control of this enzyme in the fetus. The activity of this enzyme in women in late pregnancy is increased, probably as a result of the high circulating estrogen levels (24). However, in the human fetus, placental sulfatase deficiency, leading to very low circulating fetal $E_{1}$ and $E_{2}$ levels, is not associated with low hepatic $16 \alpha$-hydroxylase activities (25). In addition, the fetuses we studied had normal serum $E_{1}$ and $E_{2}$ levels. Thus, there is no evident hormonal basis for reduced fetal hepatic 16 $\alpha$-hydroxylase activity. However, the liver in fetuses with IUGR is known to be particularly retarded in its growth (8), and certain hepatic enzymes, e.g. the gluconeogenic system, may be underactive in IUGR $(26,27)$. Definitive proof for the hypothesis that hepatic $16 \alpha$-hydroxylase activity is reduced in the IUGR group is not available and would require the demon- stration of low fetal circulating $16 \alpha-\mathrm{OH}-\mathrm{DHAS}$ levels and low $\mathrm{E}_{3}$ levels, in relation to the serum DHAS concentrations.

\section{REFERENCES}

1. Lindberg BS, Johansson EDB, Nilsson BA 1974 Plasma levels of unconjugated oestradiol-17 $\beta$ and oestriol in high risk pregnancies. Acta Obstet Gynecol Scand [Suppl] 32:37-51

2. Bashore RA, Westlake JR 1977 Plasma unconjugated estriol values in highrisk pregnancy. Am J Obstet Gynecol 128:371-380

3. Reynolds JW, Mirkin BL 1973 Urinary steroid levels in newborn infants with intrauterine growth retardation. J Clin Endocrinol Metab 36:576-58

4. Laumas KR, Malkani PK, Koshti GS, Hingorani V 1968 Invitro biosynthesis of estrogens in placentas from normal and toxemic pregnancies. Am J Obstet Gynecol 101:1062-1067

5. Babson SG, Benda GI 1976 Growth graphs for the clinical assessment of infants of varying gestational age. J Pediatr 89:814-820

6. Barnhart BJ, Carlson CV, Reynolds JW 1980 Adrenal cortical function in the postmature fetus and newborn infants. Pediatr Res 14:1367-1369

7. Turnipseed MR, Bentley K, Reynolds JW 1976 Serum dehydroepiandrostcronc sulfate in premature infants and infants with intrauterine growth retardation. J Clin Endocrinol Metab 43:1219-1225

8. Naeye RL 1965 Malnutrition: probable cause of fetal growth retardation. Arch Pathol 79:284-291

9. Yousem H, Seitchik J, Solomon D 1966 Maternal estriol excretion and fetal dysmaturity. Obstet Gynecol 28:491-494

10. Siiteri PK, MacDonald PC 1966 Placental estrogen biosynthesis during human pregnancy. J Clin Endocrinol Metab 26:751-761

11. Coyle MG 1962 The urinary excretion of oestrogen in four cases of anencephaly and one case of fetal death from cirrhosis of the liver. J Endocrinol 25:8P

12. Townsley JD, Rubin EJ, Crystle CD 1973 Evaluation of placental steroid 3 sulfatase and aromatase activities as regulators of estrogen production in human pregnancy. Am J Obstet Gynecol 117:345-350

13. Thoumsin HJ, Alsat E, Cedard L 1982 In vitro aromatization of androgens into estrogens in placental insufficiency. Gynecol Obstet Invest 13:37-43

14. Sybulski S 1969 Invitro estrogen biosynthesis from testosterone by homogenates of placentas from normal pregnancies and pregnancies complicated by intrauterine fetal malnutrition and diabetes. Am J Obstet Gynecol 105:10551062

15. Axelsson O, Nilsson BA, Johansson EDB 1978 Assessment of placental function in uncomplicated and complicated late pregnancy by estimation of unconjugated oestrogens in plasma after an intravenous injection of dehydroepiandrosterone sulphate. Acta Endocrinol 89:359-371

16. Strecker JR, Killus CM, Lauritzen C, Neumann GK 1978 The clinical value of the dehyroepiandrosterone sulfate loading test in normal and pathologic pregnancies. Am J Obstet Gynecol 131:239-249

17. Tanguy $G$, Thoumsin HJ, Zorn JR, Cedard L 1981 DHEA-S-loading test in cases of intrauterine growth retardation: Relationship between the pattern of the maternal plasma metabolites and the fetoplacental dysfunction. Gynecol Obstet Invest 12:305-316

18. Cohen H, Cohen M 1977 DHAS half-life in pregnancy, its prognostic value in high risk pregnancies. J Steroid Biochem 8:381-383

19. Tanguy G, Zorn JR, Sureau C, Cedard L 1980 Exogenous DHA-S half-life: a good index of intrauterine growth retardation. Gynecol Obstet Invest 11:170 173

20. Everett RB, Porter JC, MacDonald PC, Gant NF 1980 Relationship of maternal placental blood flow to the placental clearance of maternal plasma dehydrosoandrosterone sulfate through placental estradiol formation. Am J Obstet Gynecol 136:435-439

21. Altshuler G, Russell P, Ermocilla R 1975 The placental pathology of smallfor-gestational age infants. Am J Obstet Gynecol 121:351-359

22. Lunell NO, Sarby B, Lewander R, Nylund L 1979 Comparison of uteroplacental blood flow in normal and in intrauterine growth-retarded pregnancy. Gynecol Obstet Invest 10:106-118

23. Madden JD, Gant NF, MacDonald PC 1978 Study of the kinetics of conversion of maternal plasma dehydroisoandrosterone sulfate, to $16 \alpha$-hydroxydehydroepiandrosterone sulfate, estradiol, and estriol. Am J Obstet Gynecol 132:392-395

24. Gurpide E, Giebenhain M, Stolee A, Notation A, Dixon R, Blackard CE 1973 Stimulation of $16 \alpha$-hydroxylation of dehydroisoandrosterone sulfate by diethylstilbesterol. J Clin Endocrinol Metab 37:867-862

25. Taylor NF, Shackleton CHL 1979 Gas chromatographic steroid analysis for diagnosis of placental sulfatase deficiency: a study of nine patients. J Clin Endocrinol Metab 49:78-86

26. Haymond MW, Karl IE, Pagliara AS 1974 Increased gluconeogenic substrates in the small-for-gestational-age infant. N Engl J Med 291:322-328

27. Williams PR, Fiser RH Jr, Sperling MA, On W 1975 Effects of oral alanine feeding on blood glucose, plasma glucagon and insulin concentrations in small-for-gestational-age infants. N Engl J Med 292:612-614 